\title{
Demir eksikliği anemisi olan hastalarda alt ve üst gastrointestinal endoskopik inceleme sonuçları
}

\author{
Lower and upper endoscopic examination results in patients with iron deficiency anemia
}

Yıldız OKUTURLAR ${ }^{1}$, Aliye SOYLU ${ }^{2}$, Yeşim INAN ${ }^{1}$, Ömer ŞEKER ${ }^{1}$, Kamala GANJALIYEVA $^{1}$, Serdal ÇAKMAK ${ }^{2}$, Buğra ÖZTOSUN ${ }^{1}$, Özlem HARMANKAYA ${ }^{1}$, A. Baki KUMBASAR ${ }^{1}$

Bakırköy Dr. Sadi Konuk Eğitim ve Araştırma Hastanesi ${ }^{1} I_{c ̧}$ Hastalılan Kliniği, ${ }^{2}$ Gastroenteroloji Kliniğii, Istanbul

\begin{abstract}
Giriș ve Amaç: Gastrointestinal sistem kaynaklı kronik kan kaybı, erkek ve postmenapozal kadinlarda demir eksikliği anemisinin en sik nedenidir. Bu çalışmada, demir eksikliği anemisi nedeni ile endoskopi uygulanan hastaları, endoskopik yaklaşım ve etyolojik tanı yönünden inceledik. Gereç ve Yöntem: Ocak 2012 ve Haziran 2013 tarihleri arasında endoskopik inceleme yapılan 181 ( $K=121, E=60)$ olgu retrospektif olarak değerlendirildi. Çalışmaya hemoglobin düzeyi kadınlarda $<10 \mathrm{gr} / \mathrm{dl}$, erkeklerde $<12 \mathrm{gr} / \mathrm{dl}$ ve demir eksikliği anemisi bulguları olan hastalar dahil edildi. Kesin tanıları endoskopik biyopsi sonuçlarına göre belirlendi. Bulgular: Olguların ortalama

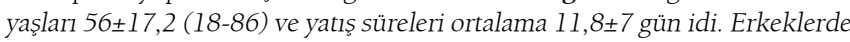

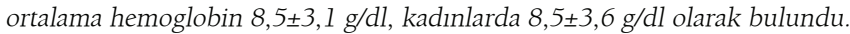
Hastaların 107 (\%59)'sine sadece gastroskopi, 53 (\%29,3)'üne gastroskopi ve kolonoskopi, 21 (\%11,6)'ine ise kolonoskopi uygulandr. Gastroskopik inceleme ( $n=160)$ uygulananlarnn \%22,5'inde eroziv gastrit, \%21,3'ünde pangastrit, \%11,3'ünde antral gastrit, \%10'unda atrofik pangastrit, \%8,1'inde gastrik ülser, \%8, l'inde polip, \% 5 'inde opere mide, \%3, 1'inde gastrik tümör, $\% 2,5$ 'inde duodenal ülser, \%5'inde diğer nedenler tespit edildi. Kolonoskopik inceleme ( $n=74)$ sonucunda ise; \%31'inde hemoroid, \%20,2'sinde polip, \%6,7'sinde kolon tümörü, \%5,4'ünde polip ve hemoroid, \%4'ünde kolonda divertiküller, \%4'ünde anjiodisplazi ve l'er hastada $(\% 1,3)$ inflamatuvar barsak hastalığı, iskemik kolit ve divertiküller, anal ülser ve terminal ileit vardı. Ayrıca bir hastada da polip, divertiküller ve hemoroid görüldü. Tüm hastaların \%5,5'ine malignite tanısı kondu. Sonuç: Demir eksikliği anemisine neden olan etyoloji oranları literatür ile uyumluydu. Ileri yaş olgularda atrofik gastrit önemini korumaktadır. Tüm yaşlarda hemoroid en sık etyolojik nedendir. Demir eksikliği anemisinde üst gastrointestinal sistem patolojisine daha sık rastlanmakla birlikte; gastrointestinal kayıp düşünülen hastalarda alt ve üst endoskopik incelemenin birlikte yapılması, kesin tanının konması açısından önemlidir.
\end{abstract}

Anahtar Kelimeler: Demir eksikliği anemisi, gastroduodenoskopi, kolonoskopi

\section{GİRISS}

Demir eksikliği anemisi (DEA) tüm dünyada ve özellikle gelişmekte olan ülkelerde yaşam kalitesini etkileyen önemli bir sağlık problemidir (1). Gelişmiş ülkelerde DEA'nın prevelansl yetişkin erkek ve postmenapozal kadınlarda \%2-5 olup; bu oran gastroenterolojiye refere edilen hastaların \%13'ünü oluşturmaktadır $(2,3)$. Gelişmekte olan ülkelerde DEA'nın en sık nedeni alım yetersizliği iken gelişmiş ülkelerde gastrointestinal patolojilerdir. Genç kadınlarda sebep kan kaybı
Background and Aims: Chronic blood loss caused by the gastrointestinal system is the most common cause of iron deficiency anemia in men and postmenopausal women. In this study, patients who underwent endoscopy as a result of iron deficiency anemia were examined in terms of endoscopic approaches and etiological diagnosis. Methods: 181 patients (60 males, 121 females) who underwent endoscopic examination between January 2012 and June 2013 were evaluated retrospectively. Patients with hemoglobin $<10 \mathrm{~g} /$ $\mathrm{dl}$ in women, hemoglobin $<12 \mathrm{~g} / \mathrm{dl}$ in men and patients with iron deficiency anemia were enrolled in this study. The definitive diagnosis was determined according to the results of endoscopic biopsy. Results: The mean age of the patients was $56 \pm 17.2$ (18-86), and the mean duration of hospitalization was $11.8 \pm 7$ days. The mean hemoglobin was $8.5 \pm 3.1 \mathrm{~g} / \mathrm{dL}$ in men and $8.5 \pm 3.6 \mathrm{~g} /$ $d L$ in females. 107 patients (59\%) underwent gastroscopy only, 53 patients (29.3\%) gastroscopy and colonoscopy, and 21 patients (11.6\%) colonoscopy only. Gastroscopic examination $(n=160)$ indicated that $22.5 \%$ had erosive gastritis, $21.3 \%$ pangastritis, $11.3 \%$ antral gastritis, $10 \%$ atrophic pangastritis, $8.1 \%$ gastric ulcer, $8.1 \%$ polyps, $5 \%$ findings of gastric surgery, $3.1 \%$ gastric tumors, 2.5\% duodenal ulcer, and 5\% other reasons.Based on the colonoscopy results $(n=74), 31 \%$ of patients had hemorrhoids, $20.2 \%$ polyps, $6.7 \%$ colon tumor, $5.4 \%$ polyps and hemorrhoids, $4 \%$ colon diverticula, and $4 \%$ angiodysplasia. Inflammatory bowel disease (1 patient, 1.3\%), ischemic colitis and diverticula (1 patient), and anal ulcer and terminal ileitis (1 patient) were also determined. In addition, polyps, diverticulitis and hemorrhoids were observed in one patient. $5.5 \%$ of all patients were diagnosed with malignancy. Conclusions: The etiology of iron deficiency anemia was consistent with the literature. Atrophic gastritis was still important in elderly patients. Hemorrhoids were the most frequent etiology in all ages. Although upper gastrointestinal tract pathology was more common in iron deficiency anemia, performing upper and lower endoscopic examination together was important for the correct diagnosis of gastrointestinal diseases in patients with chronic gastrointestinal bleeding.

Key words: Iron deficiency anemia, gastroscopy, colonoscopy

(premenapozal hipermenore) veya demir malabsorbsiyonu iken; erkeklerde ve postmenapozal kadınlarda en sık neden gastrointestinal kanaldaki kronik kan kaybıdır. Spesifik hasta gruplarında kişisel tanı yaklaşımı uygulanmalıdır. Bu tip hastalarda DEA varlığında her zaman malignensi dışlanmalıdır (4). Bu hastalarda ve hipermenoresi olmayan genç kadınlarda etyolojiye yönelik alt ve üst gastrointestinal endoskopik incelemeler yapılmalıdır. Etyolojiye yönelik değerlendirmede 
sadece gastroskopi uygulananları \%30-50'sinde DEA nedeni saptanamaz iken; gastroskopi ve kolonoskopi birlikte uygulandığında bu oran \%15'e düşmektedir. Üst ve alt endoskopik isslem yapılan hastaların \%48-71'inde DEA'nın nedeni bulunmuş; açıklanamayan olgularda ise tekrar endoskopik işlem yapılan olguların \%35'inde gözden kaçan lezyonların tespit edildiği bildirilmiştir (3). Incelemenin efektif olması için malabsorbsiyon ve atrofik gastrit gibi nedenleri dışlamak amaçlı uygun biyopsi alımı mutlak gereklidir $(5,6)$. Son zamanlarda endoskopik incelemelere rağmen devam eden anemide ince barsağın da incelenmesi (kapsül endoskopi veya çift balon enteroskopisi) ile DEA'nın tanısında başarı \%61-74'lere çıkmiştır (3). Kliniğimize DEA nedeni ile yatırılan ve aktif gastrointestinal kanama bulguları, ürolojik veya genital kanama etyolojisi saptanmayan hastalardaki endoskopi sonuçlarımızı retrospektif olarak inceleyerek değerlendirdik.

\section{GEREÇ ve YÖNTEM}

Kronik DEA nedeni ile iç hastalıkları kliniğinde Ocak 2012 ve Haziran 2013 tarihleri arasında yatırılarak araştırılan 181 ( $\mathrm{K}=121, \mathrm{E}=60)$ hastanın üst veya alt gastrointestinal sistem endoskopi sonuçları retrospektif olarak değerlendirildi. Çalışmaya hemoglobin ( $\mathrm{Hb}$ ) düzeyi kadınlarda <10 gr/dl, erkeklerde $<12$ gr/dl ve periferik kan yayması DEA bulguları ile uyumlu olan hastalar dahil edildi. Tüm olgular ürogenital veya akut kanama (melana, hematemez veya rektal kanama gibi) tariflemeyen ve oral alım eksikliği olmayan hastalardı. Klinik semptomlarının ilişkisine göre öncelik verilerek gastroduedonoskopik veya kolonoskopik incelemeler yapıldı. Gatroduodenoskopi sekiz saatlik açlık sonrası, kolonoskopi ise uygun hazırlık sonrası terminal ileum da değerlendirilecek şekilde uygulandı. Tüm üst gastrointestinal inceleme yapılan olgulara gastrik ve duodenal biyopsi yapıldı. Olguların kesin tanıları endoskopik biyopsi sonuçlarına göre konuldu. Hastaların endoskopik tanıları ve biyopsi sonuçları istatistiksel olarak değerlendirildi.

\section{BULGULAR}

Tetkik edilen 181 ( $K=121, E=60)$ olgunun ortalama yaşları $56 \pm 17,2$ (86-18) ve ortalama yatış süreleri $11,8 \pm 7$ gündü. Olguların 131'i (K=80, E=51) 45 yaşın üzerinde idi. 107 (\%59)'sine sadece gastroskopi, 53 (\%29,3)'üne gastroskopi ve kolonoskopi, 21 (\%11,6)'ine de sadece kolonoskopi uygulandi.

\section{Laboratuvar Bulguları}

Erkeklerde ortalama $\mathrm{Hb} 8,5 \pm 3,1 \mathrm{~g} / \mathrm{dl}$, kadınlarda ise 8,5 $\pm 3,6$ $\mathrm{g} / \mathrm{dl}$ olarak bulundu. Ortalama eritrosit hacmi (OEH) değerleri erkek $(72,5 \pm 10,9 \mathrm{fl})$ ve kadın $(70,4 \pm 12,1 \mathrm{fl})$ olgular arasinda farksızdi. Olguların 156'sında transferrin satürasyonu $\leq \% 50$ olup, bunların 128'inde $\leq \% 20$ idi. Ferritin düzeyi ise 134 olguda 100'ün altında idi. Bu hastalarda ortalama ferritin $14,8 \pm 19,2$, demir $28,7 \pm 33,1$, demir bağlama kapasitesi $334,1 \pm 93,1$, sedimantasyon 40,2 $\pm 25,9$ idi. B12 vitamin değeri 11 hastada 126 (Normal değer: 126-505)'nın altında idi.

\section{Endoskopik Bulgular}

Gastroskopik inceleme $(\mathrm{n}=160)$ uygulananları 36 $(\% 22,5)$ 'sinda eroziv gastrit, 34 (\%21,3)'ünde pangastrit, 18 (\%11,3)'inde antral gastrit, 16 (\%10)'sinda atrofik pangastrit, 13 (\%8,1)'ünde gastrik ülser, 13 (\%8,1)'ünde polip, $8(\% 5)$ 'inde opere mide, $5(\% 3,1)$ 'inde gastrik tümör, $4(\% 2,5)$ 'ünde duodenal ülser, 8 (\%5)'inde diğer nedenler (hiatal herni, arteriyovenöz malformasyon, cameron ülseri, özofagus varisi ve özofagusta polip) tespit edildi. B12 vitamin değeri düşük olan hastaların 1l'inin 2'sinde atrofik gastrit mevcuttu (Şekil 1). Hastaların 61'inde Helicobacter pylori pozitif olarak bulundu.

Kolonoskopik incelemede ( $\mathrm{n}=74)$ olguların; 23 (\%31)'ünde hemoroid, $15(\% 20,3)$ 'inde polip, $5(\% 6,8)$ 'inde kolon tümörü, 4 (\% 5,4)'ünde polip ve hemoroid, 3 (\%4)'ünde kolonda divertiküller, 3 (\%4)'ünde anjiodisplazi, 1 (\%1,4)'er hastada inflamatuvar barsak hastalığı, iskemik kolit ve divertiküller, anal ülser ve terminal ileit vardı. Ayrıca $1(\% 1,4)$ hastada da polip, divertiküller ve hemoroid tespit edildi. Hastaların \%21,6'sında ise lezyon saptanmadı (Şekil 2).

Tüm hastaların \%41,9'unda üst gastrointestinal, \%17,6'sında alt gastrointestinal, \%13,8'inde ise üst ve alt gastrointestinal sistemde etyolojik neden bulunmaktayd. Olguların $\% 26,5$ 'inde etyolojik neden saptanmadı ve bunların \%52'sinde pangastrit mevcuttu. Tüm hastaların \%5,5'inde malignite tespit edildi. Ayrıca olguların \%2'sinde her iki işlemde de patoloji tespit edilmedi.

\section{Histopatolojik Bulgular}

Endoskopik tanılar histopatolojik olarak doğrulandı. Gastrik ve duodenal biyopsi sonuçları Tablo l'de verildi. Kolonoskopik lezyonlara yapılan patolojik inceleme sonucu \%51,9'u adenomatöz polip, \%25,9'u hiperplastik polip, \%18,5'i adenokarsinom, \%3,7'si inflamatuvar polip olarak raporlandı.

\section{TARTIŞMA}

Kronik kan kaybına bağlı DEA olan erkek ve postmenapozal kadınlarda hastaların çoğu anemi ilişkili semptomlar ile

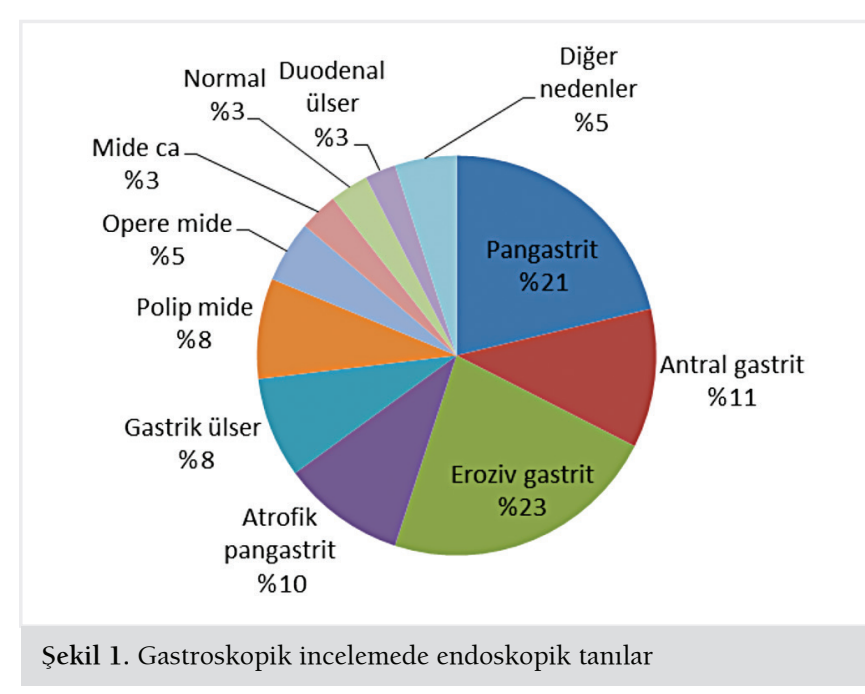




$\begin{array}{lcclccc}\text { Tablo 1. Gastroskopik biyopsilerin histopatolojik tanıları } & & \text { Duodenal Biyopsi Sonuçları } & \mathbf{n}=59 & \text { \% } \\ \text { Mide Biyopsi Sonuçları } & \mathbf{n}=141 & \% & \text { Nonspesifik kronik iltihabi proçez } & 28 & 12 & 47,4 \\ \text { Kronik yüzeyel gastrit } & 77 & 54,6 & \text { Eroziv duodenit } & 14 & 20,3 \\ \text { Atrofik kronik gastrit } & 39 & 27,7 & \text { Normal } & \text { Çölyak } & 1 & 1 \\ \text { Hiperplastik polip } & 10 & 7,1 & \text { Hiperplastik polip } & & 1,6 \\ \text { Adenokarsinom } & 5 & 3,5 & & \end{array}$

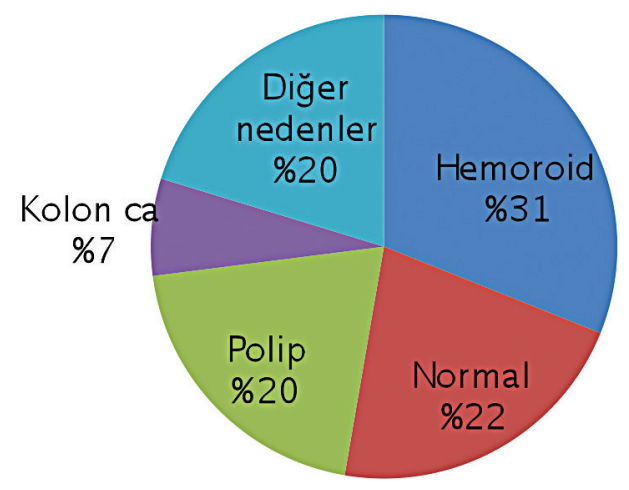

Şekil 2. Kolonoskopik incelemede endoskopik tanılar

karşımıza gelmektedir. Bu nedenle kesin tanı için gastrointestinal sistem (GIS) traktusunun tamamı değerlendirilmelidir. Ayrıca kronik DEA'sı olan hastalardaki mevcut semptomların, kanama odağını belirlemede önemli bir prediktör olmadığı da bilinmektedir. Kronik GIS kanama nedeniyle yapılan alt ve üst endoskopik incelemeler ile \%48-71 hastada kanamanın etyolojik kaynağı bulunabilmiştir (3). British Society of Gastroenterology kılavuzunun önerisi, 45 yaşından genç kadın dışındaki DEA'sı olan tüm hastalara alt/üst endoskopik incelemelerin yapilmasıdır. DEA nedeniyle yapilan 189 hastalık bir çalışmada etyolojik neden \% 76,2 oranında endoskopik olarak saptanmıştır (7). Farklı yaş gruplarına göre kronik kan kaybı veya malabsorbsiyona bağlı anemi nedeninin tetkik edildiği bir çalışmada; kanayan lezyonlar erişkin hastalarda (50-64 yaş) \%29 olup, yaşlı (65-74 yaş) hastalarda ise \%45,5 olarak daha fazla bulunmuştur. Emilim bozukluğuna bağlı (Helicobacter pylori ilişkili pangastrit, atrofik gastrit ve çölyak hastalığı) demir eksikliği erişkinlerde \%80,6; yaşlılarda ise $\% 56,2$ oranında bulunmuştur $(8,9)$. Absorbsiyon bozukluğu olan çoğu hastada dikkatli bir incelemeye rağmen endoskopik kanama odağı saptanamaz.

Etyolojik olarak gastrointestinal kaynaklı olduğu düşünülen olgularda yapılan çift endoskopik incelemede bile olguların \%5-10'unda herhangi bir lezyon bulunamayabilir (10). DEA'da etyolojik neden bulunamayan olgular tanısı zor konan (Cameron ülseri, watermelon mide, portal hipertansif gastropati, vasküler ektazi) ya da mevcut lezyonları atlanmıs olgulardır. Genel olarak atlanmıs olan lezyonların \%25 oranında olduğu düşünülmektedir. Kolonoskopide bunun ne- deni genellikle iyi bir hazırlığın yapılamamasına bağlı olarak ortaya çıkan yetersiz endoskopik incelemedir. Bizim merkezimizde de kisa süre önceki üst ve alt endoskopik incelemeleri normal olan ve DEA'sı tekrarlayan bir olgumuzda ikinci incelemede Cameron ülseri tespit edildi. Toplam 53 hastamıza üst ve alt endoskopik incelemeye rağmen \%3,7'sinde etyolojik sebep tespit edilmedi. Alt endoskopik incelemede olguları \%26,5'inde etyolojik neden saptanmadı ve bunların $\% 52$ 'sinde pangastrit mevcuttu.

Ayrıca endoskopik işlemlerin önceliğini veya etyolojiyi tespitteki faydasını araştıran bir çalışmada gastroskopik işlemde $\% 31,2$ ve kolonoskopide ise $\% 25$ oranında lezyon tespit edilmiştir. Yaşa göre yapılan değerlendirme ile postmenapozal kadınlarda gastrointestinal etyolojik sebep premenapozal kadınlara göre daha sık saptanmıştır. Kılavuzların doğrultusunda yapılan bu çalışmada da \%30'un üzerindeki hastalarda kolonoskopik inceleme uygulanmamıştır (11). Hastaya göre işlem tercihiyle ilişkili bir çalışmada DEA'lı olgularda gastroskopik inceleme ile \%31 olguda endoskopik lezyon saptanmıştır. Gastrointestinal semptomların varlığı, analjezik ve steroid kullanım öyküsü ile lezyon insidansında önemli artış da gösterilememiştir. Üst endoskopi ile lezyon saptanamayanlara kolonoskopik inceleme uygulanmıştır (12). Erkek ve postmenapozal kadınlarda saptanan DEA'da standart gastrointestinal inceleme ile olguların 2/3'ünde bir kanama nedeni bulunmaktadır (13).

Gastrointestinal kaynaklı anemide spesifik semptomlara rağmen farklı etyolojik nedenler birlikte olabileceğinden üst ve alt gastrointestinal endoskopik incelemelerin beraber yapılması önerilmektedir. Ilk işlem genelde üst endoskopik incelemedir (14). Hb değerlerinin hastalığın ciddiyeti ile ilişkili olmadığı ve gastrointestinal semptomların her iki grupta da genellikle hastalığa eşlik etmediği gösterilmiştir (15). Bizim merkezimizde de DEA'da ilk tercihimiz sıklıkla üst GIS incelemesidir. Genelde semptom gözetmeksizin her iki endoskopik girişim bu tip hastalarda planlanmaktadır. Kronik DEA'da öne çıkan bir çok semptom bizim olgularımızda da yoktu.

Akkan ve arkadaşlarının gastroskopik olarak değerlendirdiği 288 olgunun; \%3,81'inde malignite, \%3,47'sinde duodenum ülseri, \%2,43'ünde özofageal varis, \%1,73'ünde antral ülser, \%61,45'inde endoskopik gastropati, \%0,69'unda çölyak hastalığı, \%7,63'ünde opere mide saptanırken, \%18,75'inde kanama nedeni bulunamamıștır (16). Farklı bir çalışmada DEA olan 668 olguda, bariz kanama, yetersiz diyet, kronik 
hastalıklar ve malignensi dişlandıktan sonra 71 hastaya (51 kadin) antral ve duodenal biyopsili gastroskopi ve kolonoskopi yapılmış ve tüm hastaların \%85'inde DEA'nın nedeni bulunmuştur (15). Ülkemizde yapılan farklı bir çalışmada ise gastrointestinal sistemden kronik kanaması olduğu düşünülen 72 olgunun tamamina alt ve üst endoskopik inceleme yapılmış ve \%16,6'sında alt, \%61'inde üst gastrointestinal lezyon saptanmıştır. Olguların \%22,2'sinde ise etyoloji bulunamamıştır (13). Hafif anemisi olan ve gaytada gizli kan (GGK) testi negatif olan daha genç hastalara ise öncelikle gastroskopi yapılması önerilmektedir (17). Bizim olgularımızın \%59'una sadece gastroskopi, \%29,3'üne önce gastroskopi ve ardından kolonoskopi, \%11,6'sina da sadece kolonoskopi uyguland.

DEA'sı olan yetişkin erkek ve postmenapozal kadınlarda, kanama etyolojisine yönelik alt-üst endoskopik inceleme ile GGK pozitif olanların \%75'inde, negatif olanların \%63'ünde lezyon saptanmiştır (18). Ileri yaş olgularda gastrointestinal lezyonun lokalizasyonunu saptamada bidireksiyonel endoskopi yüksek oranda sensitif ve spesifiktir. Öncelikle malignite olasılığı nedeniyle kolonoskopi ve ardından gastroskopi ile kaynak yine de saptanamaz ise demir tedavisi ve gözlem önerilmektedir. Eğer tedaviye yanıt alınamaz ise uygun olgularda ince barsak araştırması ve diğer girişimlerin yapılması önerilmiştir (19).

DEA'sı olan hastaların \%11,2'sinde gastrointestinal malignite bulunmuştur. DEA'sı olanlarda GIS malignite için anlamlı risk faktörü, 50 yaş üstü $\mathrm{Hb}$ değeri $\leq 9$ gr/dl olan erkek hastalar olarak bulunmuştur (20). Diğer bir çalışmada anemisi olan ve olmayan demir eksikliği olanlar araştırılmış, erkek ve postmenapozal kadınlarda GIS malignite oranı anemisi olanlarda \%6, olmayanlarda ise \%1 bulunmuştur (21). Bir çalışmada da 749 anemik (ferritin değeri $\leq 50 \mathrm{ng} / \mathrm{mL}$ ve total demir bağlama kapasitesi $\geq 300 \mathrm{mg} / \mathrm{dL}$ ) ve 769 anemik olmayan toplam 1518 hasta alınmış ve lezyon bulunma oranı sırasıyla

\section{KAYNAKLAR}

1. Milman N. Anemia--still a major health problem in many parts of the world! Ann Hematol 2011;90:369-77.

2. Gunter EW, Lewis BG, Koncikowski SM. Laboratory procedures used for the Third National Health and Nutrition Examination Survey (NHANES III), 1988-1994. US Dep Heal Hum Serv Public Heal Serv Centers Dis Control Prev Natl Cent Environ Heal Atlanta, GA, Natl Cent Heal Stat Hyattsville, MD. 1996.

3. Bull-Henry K, Al-Kawas FH. Evaluation of occult gastrointestinal bleeding. Am Fam Physician 2013;87:430-6.

4. Liu K, Kaffes AJ. Iron deficiency anaemia: a review of diagnosis, investigation and management. Eur J Gastroenterol Hepatol 2012;24:109-16.

5. Luzina E, Lareva N. Anemia and gastrointestinal tract diseases. Ter Arkh 2013;85:102-5.

6. Walker MM, Talley NJ. Clinical value of duodenal biopsies--beyond the diagnosis of coeliac disease. Pathol Res Pract 2011;207:538-44.

7. Milano A, Balatsinou C, Filippone A, et al. A prospective evaluation of iron deficiency anemia in the GI endoscopy setting: Role of standard endoscopy, videocapsule endoscopy, and CT-enteroclysis. Gastrointest Endosc 2011;73:1002-8

8. Selek S, Cosar N, Kocyigit A, et al. PONl activity and total oxidant status in patients with active pulmonary tuberculosis. Clin Biochem 2008;41:140-4
$\% 24,6$ ve \%22,8 olarak benzer bulunmuştur. Üst GíS lezyon oranı sirasiyla \%11,9 ve \%12,5, alt GIS lezyon oranı da sirasıyla \%13,6 ve \%11,4 oranlarında olmak üzere her iki grupta da benzer bulunmuştur. Bununla beraber GIS malignite oranı anemik $(\% 5,1)$ olanlarda olmayanlara $(\% 0,7)$ göre daha yüksek oranda bulunmuştur (22).

Kronik kan kaybının olmadığı DEA'da sebepler arasında çölyak hastalığı, gastrik cerrahi operasyon varlığı, Helicobacter pylori veya kronik atrofik gastrit gibi hastalıklar da yer almaktadır. Bu nedenle bu hastalara üst endoskopik incelemede antral ve fundus biyopsisi ile duodenal biyopsi yapılmalıdır. Yapılan çalışmalarda DEA'sı olanlarda çölyak prevelansı \%315, atrofik gastrit prevalansı \%20-27 olarak gösterilmiştir $(23,24)$. Bizim çalışmamızda da çölyak hastalığı \%2,8 ve atrofik gastrit \%10 oranında bulunmuştur.

Laboratuvar çalışmaları ile doğrulanan DEA'da diyet ile olan alım azlığı, demir ihtiyacında artış, üriner ve genital kayıp gibi gastrointestinal sistem dışı kan kaybına bağlı nedenler dışlandıktan sonra endoskopik incelemeler uygulanmalıdır. Genelde ileri yaşta gastrointestinal nedenler ön planda düşünülmekle birlikte, bir hastamıda semptomsuz mesane kanseri tespit ettik. Invaziv endoskopik işlemler öncesinde diğer DEA nedenlerinin dikkatli irdelenmesi önemlidir.

Kronik kan kaybı Hb düzeyinde anlamlı düşüşler ile karşımiza gelmektedir. DEA'ya neden olan etyolojik tanı oranları bizim olgularımızda da literatür ile uyumluydu. Ileri yaş hastalarda atrofik gastrit komponenti önemini korumaktadır. Tüm hastalarımıza kolonoskopik inceleme yapılamamasına rağmen, tüm yaşlarda saptanabilen hemoroid en sik etyolojik nedendir. DEA'da üst gastrointestinal sistem patolojisine daha sık rastlanmakla birlikte; gastrointestinal kayıp düşünülen erişkin erkeklerde ve postmenapozal kadınlarda alt ve üst endoskopik incelemeler birlikte yapılmalıdır.
9. Vannella L, Aloe Spiriti MA, Di Giulio E, et al. Upper and lower gastrointestinal causes of iron deficiency anemia in elderly compared with adult outpatients. Minerva Gastroenterol Dietol 2010;56:397-404.

10. Raju GS, Gerson L, Das A, Lewis B. American Gastroenterological Association (AGA) Institute Technical Review on Obscure Gastrointestinal Bleeding. Gastroenterology 2007;133:1697-717.

11. Luman W, Ng KL. Audit of investigations in patients with iron deficiency anaemia. Singapore Med J 2003;44:504-10.

12. Tan CC, Guan R, Tay HH, et al. The diagnostic yield of upper gastrointestinal endoscopy in the investigation of anaemia. Singapore Med J 1991;32:157-9.

13. Kurtoğlu E, Kayaçetin E, Uğur A. Demir Eksikliği Anemisi Saptanan Erkeklerde ve Postmenapozal Kadınlardaki Alt ve Üst Gastrointestinal Sistem Bulguları. MN Klinik Bilim Dr 2004;10:251-4.

14. McIntyre AS, Long RG. Prospective survey of investigations in outpatients referred with iron deficiency anaemia. Gut 1993;34:1102-7.

15. Annibale B, Capurso G, Chistolini A, et al. Gastrointestinal causes of refractory iron deficiency anemia in patients without gastrointestinal symptoms. Am J Med 2001;111:439-45

16. Çetinkaya ZA, Sezikli M, Güzelbulut F, Altınöz ME. Demir eksikliği anemili hastalarda gastrointestinal endoskopik inceleme sonuçları (Results of gastrointestinal endoscopic examinations in patients with iron). Dicle Tip Derg 2011;38:155-9. 
17. Capurso G, Baccini F, Osborn J, et al. Can patient characteristics predict the outcome of endoscopic evaluation of iron deficiency anemia: A multiple logistic regression analysis. Gastrointest Endosc 2004:59:766-71.

18. Kepczyk T, Kadakia SC. Prospective evaluation of gastrointestinal tract in patients with iron-deficiency anemia. Dig Dis Sci 1995;40:1283-9.

19. Moses PL, Smith RE. Endoscopic evaluation of iron deficiency anemia. A guide to diagnostic strategy in older patients. Postgrad Med 1995;98:213-6.

20. James MW, Chen C-M, Goddard WP, et al. Risk factors for gastrointestinal malignancy in patients with iron-deficiency anaemia. Eur J Gastroenterol Hepatol 2005;17:1197-203.

21. Ioannou GN, Rockey DC, Bryson CL, Weiss NS. Iron deficiency and gastrointestinal malignancy: A population-based cohort study. Am J Med 2002;113:276-80.
22. Park JS, Park DI, Park SK, et al. Endoscopic evaluation of significant gastrointestinal lesions in patients with iron deficiency with and without anaemia: a Korean Association for the Study of Intestinal Disease study. Intern Med J 2009;39:441-6.

23. Zhu A, Kaneshiro M, Kaunitz JD. Evaluation and treatment of iron deficiency anemia: a gastroenterological perspective. Dig Dis Sci 2010;55:548-59.

24. Bermejo F, García-López S. A guide to diagnosis of iron deficiency and iron deficiency anemia in digestive diseases. World J Gastroenterol 2009;15:4638-43 